\title{
"A STUDY OF ATTITUDE AND MOTIVATION OF ENGLISH LANGUAGE LEARNERS AT SECONDARY SCHOOL STUDENTS OF HYDERABAD-KARNATAKA REGION"
}

\author{
*Ranju T Nair, ** Dr.U.K.Kulkarni \\ *Research Scholar, \\ **Associate Professor \&Research Guide \\ Dept.of Education, Karnataka State Akkamahadevi Women's University,Jnanashakti Campus, Torvi, Vijayapura-586108. e- \\ mail:ukkulkarni1970@gmail.com
}

\begin{abstract}
This study was attempted to investigate the attitude and motivation of English Language Learners at secondary school students of Hyderabad-Karnataka region. A standardized questionnaire was administered in the form of survey to 900 IX standard students from Hyderbad-Karnataka region (Bellary, Bidar, Kalabugi, Koppal,Raichur and Yadgir) to collect data regarding their motivation and attitude towards learning English Language.The collected data was statistically analyzed using suitable statistical methods like mean,standard deviation, $t$ test,one way analysis of varience (ANOVA). The result revealed that there is a significant difference between the gender and locality of the school,type of school,type of management. This study recommended that the relevant language improvement programs and activities are also discussed in accordance with the students language difficulties as communicated in the open-ended questions to increase their motivation and attitude in English language.Hence it was concluded that more classroom activities in the study of English enhance pupils attitude and motivation to learn English.
\end{abstract}

\section{Keywords}

Attitude, Motivation, secondary school students, and Hyderabad-Karnataka region.

Article Received: 18 October 2020, Revised: 3 November 2020, Accepted: 24 December 2020

\section{INTRODUCTION:}

English has played an irrefutable role in Indian society in both its public and private sector. English even today continues to act as an indispensable 'Link' language. English symbolizes in Indian minds better education, better culture and better intellect.It is still freely used in administration,judiciary,in education and even for literary purposes in India. English as stated by Timothy.J. Scrase "is not only important in getting a better job, but it is everywhere in social interaction. If you can't speak it, then you are nobody". This view makes it clear that English occupies a place of prestige in our country. People belonging not only to a different language groups but also to the same speech community make use of English in their inter-personal communication.

It is quiet interesting to note that India, a multilingual nation, is the third largest English speaking country after the US and UK. In India, it is increasingly being perceived as a 'must-know' language. It has now become a ladder for upward social mobility and a window to the world. Such is the demand for learning this language that a variety of English coaching centers and privatetution shops, English medium schools which are mushrooming in a large numbers and are easy to spot almost everywhere in our country, even after independence,clearly indicate the respectable position this language enjoys in the minds of the democratic Indians.

In English language learning context, there are various factors that influence the learning process such as attitude, motivation, anxiety, learning achievement, aptitudes, intelligence are most important issues that should be taken into account.While discussing factors affecting the teaching-learning process. Attitudes are a condition for,and a result of, effective instruction; therefore,studies were conducted in various 
educational fields to examine strategies and techniques that could contribute once age,personalities etc.The matter of learner's attitude is acknowledged as one of the most important factors that impact on learning language.So, developing students attitudes towards learning is considered to be one of them to developing students attitudes towards learning.

\section{ATTITUDES:}

There will be some definitions of attitudes in this part based on some experts. Attitudes actually are internal states that influence what the learners likely to do.The internal state is some degree of positive /negative or favourable/unfavourable reaction towards an object. Teachers,learners and researchers will all agree that a high motivation and a positive attitude towards a second language and its community help second language learning. Attitudes towards a particular language might be either positive or negative. Language attitude is an important concept because it plays a key role in language learning and teaching.

Brown (2000) uses the term 'attitudes' to refer to the set of beliefs that the learner holds towards members of the target language group and also towards his own culture. Wenden(1991) suggested a broader definition of the concept "attitudes". He says that the term attitude contains three components namely cognitive, affective and behavioral. A cognitive components is made up of the beliefs and ideas or opinions about the object of the attitude.The affective one refers to the feeling and emotions that one has towards an object, likes'or 'dislikes','with'or 'against'. Finally, the behavioral component refers to one's consisting actions or behavioral intentions towards the object.

\section{MOTIVATION:}

The basic force behind all human activities nothing but motivation. According to Guilford,: Motive is a particular internal factor or condition that tends to initiate and to sustain activity".Thus motivation includes all those internal conditions which help to begin in activity and pursue it with vigour. Motive is different from stimulus because it is there even before the stimulus may not work.There can be one motive behind different actions and different motives behind the same action. Motivation is the very heart of the learning process. Motivation has been classifieds as intrinsic and extrinsic.Intrinsic motivation emerges from within and directly linked with the natural instincts,urges and impulses of the organism.The individual who is intrinsically motivated performs an act because he is naturally gets interested in the activity and derives satisfaction in performing. Extrinsic motivation refers to condition that are external to the activity and the individual. Here the source of satisfaction does not lie within the task.That is ,such kind of motivation has no functional relationship to the task, reading books in order to pass the examination is an example.

NEED OF THE STUDY:

Student's academic performance occupies a very important place in education as well as in the learning process, Attitude and Motivation are some of the factors that should affect the academic excellence. It's considered as a key criterion to judge ones total potentialities. Some times students failed to develop these things while learning English language. It is most important to help pupils to develop their attitude and motivation for the achievement in English. So that they may gain a sense of achievement in English and recover their confidence and interest in English language.

\section{OBJECTIVES OF THE STUDY:}

Following are the objectives of the present study

1. To find out the relationship between students attitudes and grades of secondary school students of Hyderabad-Karnataka region.

2. To find out the difference between students attitudes towards learning English,with reference to Gender,type of school,Locality and Medium. 
3. To find out the relationship between their grades and motivation levels of secondary school students of Hyderabad-Karnataka region.

4. To find out the difference between their motivation levels with reference to Gender,type of school,Locality and Medium of secondary school students of HyderabadKarnataka region.

5. To find out the learning behaviors of secondary school students according to their motivational levels.

\section{HYPOTHESIS OF THE STUDY:}

Following are the Hypothesis of the present study

$>$ There is no significant relationship between students attitudes and grades of secondary school students in Hyderabad-Karnataka region.

$>$ There is no significant difference between students attitudes towards learning English,with reference to Gender,type of school,Locality and Medium.

> There is no significant relationship between their grades and motivation levels of secondary school students of HyderabadKarnataka region.

$>$ There is no significant difference between their motivation levels with reference to Gender,Type of school,Locality and Medium of secondary school students of HyderabadKarnataka region.

$>$ There is no significant relationship between learning behaviors of secondary school students according to their motivational levels.

\section{METHODOLOGY OF THE STUDY:}

In this study, Descriptive survey method was used. According to John W Best (1977,p.15) Descriptive research describes what is. It involves the description, recording, analysis and interpretation of the conditions that now exist.

\section{Tools used in the study:}

For measuring attitude and motivation of English language learners the following tools were used

$>$ Attitude scale developed by the research investigator.

$>$ Motivation scale developed by the research investigator.

\section{Sampling techniques Used:}

The study covers the 900 secondary students $\left(9^{\text {th }}\right.$ standard) of Hyderabad-Karnataka region(

Bellary,Bidar,Kalaburgi,Koppal,Raichur,Yadgir). Further division will be made into rural and urban,type of school,Gender,Locality and medium of school.From each districts the researcher collected 150 samples.

\section{Statistical Technique Used:}

In this study, Descriptive statistics-mean and standard deviation,deferential Analysis:t-test, ANOVA(one way \& two way), Correlation coefficient (Karl Pearson's) technique were used.

\section{Procedure of Data Collection:}

After selecting sample, the researcher made personal contact to the principal's of the respective schools, after granting permission from principal,the researcher distributed the attitude and motivation scale and collected the data from the secondary school students of Hyderabad Karnataka region.

DATA

ANALYSIS

AND INTERPRETATIONS:

The data analysis and interpretation consists of the presentation and analysis of the observed findings of the study using a various statistical procedures which are used for analysis quantitative data.

Table 1: Attitude and Motivation scores towards learning English of different districts (Bellary,Bidar,Kalaburgi,Koppal,Raichur and Yadgir) in Hyderabad-Karnataka region.

\begin{tabular}{|l|l|l|l|l|l|}
\hline Variables & Districts & Mean & SD & SE & 95\% CI FOR MEAN \\
\hline
\end{tabular}




\begin{tabular}{|l|l|l|l|l|l|l|}
\hline \multicolumn{4}{|c}{} & Lower Bound & Upper Bound \\
\hline Attitude & Bellary & 208.45 & 6.58 & 0.54 & 207.39 & 209.51 \\
\hline \multirow{5}{*}{} & Bidar & 208.77 & 10.15 & 0.83 & 207.14 & 210.41 \\
\cline { 2 - 7 } & Kalaburgi & 201.45 & 13.98 & 1.14 & 199.20 & 203.71 \\
\cline { 2 - 7 } & Koppal & 198.43 & 9.85 & 0.80 & 196.84 & 200.02 \\
\cline { 2 - 7 } & Raichur & 196.40 & 6.38 & 0.52 & 195.37 & 197.43 \\
\cline { 2 - 7 } & Yadgir & 209.33 & 7.93 & 0.65 & 208.05 & 210.61 \\
\cline { 2 - 7 } & Total & 203.81 & 10.84 & 0.36 & 203.10 & 204.52 \\
\hline \multirow{5}{*}{ Motivation } & Bellary & 118.14 & 3.15 & 0.26 & 117.63 & 118.65 \\
\cline { 2 - 7 } & Bidar & 116.13 & 5.16 & 0.42 & 115.30 & 116.97 \\
\cline { 2 - 7 } & Kalaburgi & 114.15 & 5.36 & 0.44 & 113.28 & 115.01 \\
\cline { 2 - 7 } & Koppal & 111.21 & 6.21 & 0.51 & 110.21 & 112.22 \\
\cline { 2 - 7 } & Raichur & 107.97 & 4.93 & 0.40 & 107.17 & 108.76 \\
\hline & Yadgir & 117.33 & 4.33 & 0.35 & 116.63 & 118.03 \\
\hline & Total & $\mathbf{1 1 4 . 1 5}$ & $\mathbf{6 . 1 0}$ & $\mathbf{0 . 2 0}$ & $\mathbf{1 1 3 . 7 6}$ & $\mathbf{1 1 4 . 5 5}$ \\
\hline
\end{tabular}

The above table clearly says that the mean \#SD of attitude scores towards learning English of student learners in Hyderabad Karnataka region is $203 \# 10,84$,in which,the student learners belongs to Raichur districts(196.40\#6.38) and Koppal district (198.43\#9.85) have lesser attitude scores as compared to student learners belongs to Bellary district (208.45\#6.58),Bidar district (208.77\#10.15),Kalaburgi district (201.45\#13.98) and Yadgir district (209.33\#7.93) have higher attitude scores towards learning English in the study.The standard error and 95\% confidence interval for mean of attitude scores are also presented in the above table. The mean\#SD of motivation scores towards learning English of student learners in Hyderabad-Karnataka region is 114.15\#6.10,in which,the student learners belongs to Raichur district(107.97\#4.93) and Koppal district(111.21\#6.21) have lesser motivation scores as compared to student learners belongs to Bellary district (118.14\#3.15),Bidar district (116.13\#5.16),Kalaburgi region (114.15\#5.36) and Yadgir (117.33\#4.33) have higher motivation scores towards learning English in the study.

TABLE 2:- Attitude and motivation scores towards learning English of student learners in HyderabadKarnataka region in respect of gender.

\begin{tabular}{|c|c|c|c|c|c|c|}
\hline Variables & Gender & mean & SD & SE & \multicolumn{2}{|c|}{$95 \%$ CI for mean } \\
\hline & & & & & Lower bound & upper bound \\
\hline \multirow[t]{3}{*}{ Attitude } & male & 201.71 & 10.47 & 0.48 & 200.78 & 202.65 \\
\hline & Female & 206.20 & 10.79 & 0.53 & 205.16 & 207.23 \\
\hline & Total & 203.81 & 10.84 & 0.36 & 203.10 & 204.52 \\
\hline \multirow[t]{3}{*}{ Motivation } & male & 113.19 & 6.40 & 0.29 & 112.61 & 113.76 \\
\hline & Female & 115.26 & 5.53 & 0.27 & 114.73 & 115.79 \\
\hline & Total & 114.15 & 6.10 & 0.20 & 113.76 & 114.55 \\
\hline
\end{tabular}

It clearly seen that, the mean\#SD of attitude scores towards learning English of student learners in Hyderabad-Karnataka region is 203.81\#1084, in which,the female student learners have higher attitude scores (206.20\#10.79) as compared to male student learners (201.71\#10.47) in the study. The mean \#SD of motivation scores towards learning English of student learners in Hyderabad-Karnatake region is ( $114.15 \# 6.10)$, in which,the female student learners have higher 
motivation scores(115.26\#5.53) as compared to

male student learners(113,19\#6.40) in the study.

TABLE-3: Attitude and motivation scores towards learning English of Kannada, English and Urdu medium student learners in Hyderabad Karnataka region.

\begin{tabular}{|c|c|c|c|c|c|c|}
\hline Variables & Mediums & Mean & SD & SE & \multicolumn{2}{c|}{ 95\% CI For mean } \\
\hline & & & & & L.B & U.B \\
\hline Attitude & Kannada & 205.57 & 9.52 & 0.53 & 204.52 & 206.62 \\
\hline & English & 207.52 & 9.68 & 0.56 & 206.42 & 208.62 \\
\cline { 2 - 7 } & Urdu & 197.81 & 10.97 & 0.66 & 196.52 & 199.11 \\
\cline { 2 - 7 } & Total & $\mathbf{2 0 3 . 8 1}$ & $\mathbf{1 0 . 8 4}$ & $\mathbf{0 . 3 6}$ & $\mathbf{2 0 3 . 1 0}$ & $\mathbf{2 0 4 . 5 2}$ \\
\hline Motivation & Kannada & 114.36 & 5.41 & 0.30 & 113.76 & 114.95 \\
\hline & English & 114.75 & 5.39 & 0.31 & 114.14 & 115.37 \\
\cline { 2 - 7 } & Urdu & 113.28 & 7.35 & 0.44 & 112.41 & 114.14 \\
\cline { 2 - 7 } & Total & $\mathbf{1 1 4 . 1 5}$ & $\mathbf{6 . 1 0}$ & $\mathbf{0 . 2 0}$ & $\mathbf{1 1 3 . 7 6}$ & $\mathbf{1 1 4 . 5 5}$ \\
\hline
\end{tabular}

It clearly says that the mean\#SD of attitude scores towards learning English of student learners in Hyderabad-karnataka region is 203.81\#10.84,in which,the English medium student learners have higher attitude scores(207.52\#9.68) followed by Kannada medium student learners have higher attitude scores(205.57\#9.52) and Urdu medium student learners have least attitude scores towards learning English $(197.81 \# 10,97)$ in the study. The
mean\#SD of motivation scores towards learning English of student learners in HyderabadKarnataka region is $114.15 \# 6.10$,in which,the English medium student learners have higher motivation scores(114.75\#5.39) followed by Kannada medium student learners have higher motivation scores(114.36\#5.41) and Urdu medium student learners have least motivation scores towards learning English (113.28\#7.35) in the study.

TABLE-4:-Attitude and motivation scores towards learning English of rural and Urban student learners in Hyderabad-Karnataka region

\begin{tabular}{|l|l|l|l|l|l|l|}
\hline Variables & Location & mean & SD & SE & \multicolumn{2}{|c|}{ 95\% CI for mean } \\
\hline & & & & & Lower Bond & Upper Bond \\
\hline Attitude & Rural & 202.28 & 11.52 & 0.54 & 201.22 & 203.33 \\
\hline & Urban & 205.40 & 9.85 & 0.47 & 204.48 & 206.33 \\
\hline & Total & $\mathbf{2 0 3 . 8 1}$ & $\mathbf{1 0 . 8 4}$ & $\mathbf{0 . 3 6}$ & $\mathbf{2 0 3 . 1 0}$ & $\mathbf{2 0 4 . 5 2}$ \\
\hline \multirow{2}{*}{ Motivation } & Rural & 113.74 & 6.42 & 0.30 & 113.15 & 114.33 \\
\hline & Urban & 114.59 & 5.72 & 0.27 & 114.06 & 115.13 \\
\cline { 2 - 7 } & Total & $\mathbf{1 1 4 . 1 5}$ & $\mathbf{6 . 1 0}$ & $\mathbf{0 . 2 0}$ & $\mathbf{1 1 3 . 7 6}$ & $\mathbf{1 1 4 . 5 5}$ \\
\hline
\end{tabular}

The above table says that the mean\#SD of attitude scores towards learning English of student learners in Hyderabad Karnataka region is 203.81\#10.84, in which, the urban student learners have higher attitude scores(205.40\#9.85) as compared to their counterparts i.e rural school students $(202.28 \# 11,52)$ have lesser attitude scores towards learning English in the study. The mean\#SD of motivation scores towards learning English of student learners in Hyderabad 
Karnataka region is 114.15\#6.10), in which,the urban school student learners have higher motivation scores(114.59\#5.72) as compared to their counterparts i.e rural school students learners (113.74\#6.42) have lesser motivation scores towards learning English in the study.

TABLE-5: Attitude and motivation scores towards learning English of government, aided and unaided school student learners in Hyderabad-Karnataka region

\begin{tabular}{|c|c|c|c|c|c|c|}
\hline Variables & Types of & Mean & SD & \multirow[t]{2}{*}{ SE } & \multicolumn{2}{|c|}{$95 \%$ CI for mean } \\
\hline & & & & & $\begin{array}{l}\text { Lower } \\
\text { bound }\end{array}$ & $\begin{array}{l}\text { upper } \\
\text { bound }\end{array}$ \\
\hline Attitude & Government & 199.97 & 11.48 & 0.64 & 194.71 & 201.23 \\
\hline & Aided & 206.73 & 11.33 & 0.65 & 205.44 & 208.01 \\
\hline & Unaided & 205.06 & 7.94 & 0.47 & 204.13 & 205.99 \\
\hline & Total & 203.81 & 10.84 & 0.36 & 203.10 & 204.52 \\
\hline Motivation & Government & 115.13 & 6.52 & 0.36 & 114.41 & 115.85 \\
\hline & Aided & 112.95 & 5.80 & 0.34 & 112.29 & 113.61 \\
\hline & Unaided & 114.33 & 5.68 & 0.34 & 113.66 & 115.00 \\
\hline & Total & 114.15 & 6.10 & 0.20 & 113.76 & 114.55 \\
\hline
\end{tabular}

The above table says that the mean\#SD of attitude scores towards learning English of student learners in Hyderabad-Karnataka region is (203.81\#10.84), in which,the aided school student learners have higher attitude scores (206.73\#11.33) as compared to unaided school student learners (205.06\#7.94) followed by government school student learners (199.97\#11.48) have lesser attitude scores towards learning English in the study. The mean\#SD of motivation scores towards learning English of student learners in Hyderabad-Karnataka region is 114.15\#6.10), in which, the unaided school student learners have higher motivation scores(114.33\#5.68) as compared to aided school student learners (115.13\#6.52) have lesser motivation scores towards learning English in the study.The standard error and 95\% confidence interval for mean of motivation scores are also presented in the table.

\section{IMPORTANT FINDINGS:}

$>$ Bellary,Bidar,Kalaburgi and Yadgir have higher attitude towards learning English and Raichur,Koppal have lesser attitude towards learning English.
$>$ Bellary,Bidar,Kalaburgi and Yadgir have higher motivation scores towards learning English and Raichur and Koppal have lesser motivation scores.

$>$ Female students have high attitude towards English than male students.

$>$ Female students have high motivation towards Learning English than male students.

> English medium students have high attitude towards learning English as compared to Kannada medium and Urdu medium.

$>$ English medium students have higher motivation scores as compared to Kannada medium and English medium.

> Urban student learners have high attitude as compared to rural school student learners.

> Urban student learners have high motivation scores as compared to rural school student learners.

$>$ Aided school students have high attitude towards learning English as followed by unaided and Government school students.

> Unaided school students have high motivation scores as followed by aided and government school students. 


\section{EDUCATIONAL IMPLICATIONS:}

Following are the some of the educational implications drawn from the findings.

1. Teachers can make a valuable contribution in developing a friendly relationship with their students,in order to develop a positive attitude towards learning English language.

2. Positive psychological class room atmosphere needed for learning language, and the errors are considered as a natural part of the process of learning English language.

3. Teachers should motivate the students to learn better English, by highlighting its importance as they need English for getting employment purpose in future.

4. Teachers and parents should always encourage learners to read materials written in English like newspapers and magazines.

5. Teachers who qualify to teach English must have received a relevant training and qualification in English.If the above condition is taken care of learners would receive proper knowledge which would help them to develop confidence and they will be competent in the world.

\section{CONCLUSION:}

The government, Educationist and Teaching community are interested in providing quality education, which will lead to produce more achievement.Students are significantly differing in their attitude based on the gender,locality of the school,type of management etc.This clearly underlines the need for special attention in this area.As in depth study may be conducted to find out the reasons for significant differences in their attitude and motivation.It is widely accepted that an important predictor of success in learning English language is the attitude and motivation of the students.

\section{REFERENCES:}

[1] Ahuja,g.c.and aruja,d(1964) English in India:its present and future.Bombay:area publishing house.
[2] Dornyei,z.(2002).Motivational strategies in the language classroom.Cambridge:University Press.

[3] Ellis,R.(1997).Second language acquisition.Oxford: Oxford University Press.

[4] Gardiner,R.\&Lambert,W.(1972)Attitudes and motivation in second language learning.Rowley,MA: Newbury House.

[5] Gardiner,R.C.(1985).Social psychological and second language learning:The role of attitudes and motivation.London: Edward Arnold Publishers.

[6] Krishna kumar,R and Ambedkar,V.(2009),'Pupils attitude towardsEnglish in relationto certain selected variables',Meston Jounal of Research in Education,Volume-4,Issue No.1,page No-10,Meston College of Education.

[7] Lightbown,p.m.,\& Spada,N.(1999).How languages are learned.Oxford:Oxford University.

[8] Masgoret,A.M.and

Gardiner,R,C.(2003).Attitude,Motivation,a nd Second language Learning: A MetaAnalysis of studies conducted by Gardiner and

Associates.Language

Learning,53:1,123-163.

[9] Mc lean,r(1997):selected attitudinal factors related to students success in high school.Alberta jounal of educational research,vol.43,(2-3),pp.165-168.

[10] Nirmala Sudararaj,(2010),"Attitude towards English Education of the B.Ed,Trainees of Tamil Nadu Open University",Meston Journal of Research in Education,Volume-4,Issue No.2,page No9,Meston College of Education.

[11] Petrides,j.r.(2006).Attitudes and motivation and their impact on the performance of young English language learners.Jounal of Language and Learning,5:1,1-20. 
[12] Snow,A.,and Cohen,L.K.(2006),"Students attitude towards English and the Humanistic",The Jounal of Educational Research,vol 61,No.10.

[13] Spaulding,C.L.(1992).Motivation in the classroom.USA:McGraw-Hill,Inc.

[14] Venugopal,G.(2005),"The influence of teacher attitude and expectations on pupils achievement in English",Experiments in Education,vol.XXXIII,No.1.

[15] Ward,Willaim,H.,Jr.(2007),"A test of the association of class size to students attitude toward English",Jounal of research in English teaching. 